\title{
Human embryos in a dish - modeling early embryonic development with pluripotent stem cells
}

\author{
Xiukun Wang and Guang $\mathrm{Hu}^{*}$
}

\begin{abstract}
Stem cell-based embryo models present new opportunities to study early embryonic development. In a recent study, Kagawa et al. identified an approach to create human pluripotent stem cell-based blastoids that resemble the human blastocysts. These blastoids efficiently generated analogs of the EPI, TE, PrE lineages with transcriptomes highly similar to those found in vivo. Furthermore, the formation of these lineages followed the same sequence and pace of blastocyst development, and was also dependent on the same pathways required for lineage specification. Finally, the blastoids were capable of attaching to stimulated endometrial cells to mimic the process of implantation. While more comprehensive analysis is needed to confirm its validity and usefulness, this new blastoid system presents the latest development in the attempt to model early human embryogenesis in vitro.
\end{abstract}

Keywords: Pluripotent stem cells, Stem cell-based embryo models, Blastoid

\section{Main Text}

Understanding human embryonic development can provide important insights to both basic research and clinical applications. However, it is difficult to study the natural development of human embryos for ethical and technical reasons, and it is also challenging to carry out experiments in vitro due to the lack of embryonic materials. As an alternative, stem cell-based embryo models have opened an unprecedented avenue for modeling embryogenesis. For example, mouse blastocyst-like structures have been generated using various pluripotent stem cells (PSCs) or a mixture of pluripotent and extraembryonic stem cells. These structures form by self-organization under the appropriate culture conditions and recapitulate many of the early developmental events (reviewed in Posfai et al. 2021; Rossant and Tam 2021)). More recently, human stem cell-based embryo models have also been

\footnotetext{
*Correspondence: hug4@niehs.nih.gov

Epigenetics and Stem Cell Biology Laboratory, National Institute

of Environmental Health Sciences Research Triangle Park, Durham, NC
} 27709, USA created (Fan et al. 2021; Liu et al. 2021; Sozen et al. 2021; Yanagida et al. 2021; Yu et al. 2021), but the fidelity to which the human models mimic blastocyst development has been challenged (Zhao et al. 2021).

In a recent issue of Nature, Kagawa et al. reported a new approach to generate human blastocyst-like structures in vitro using naïve human PSCs (Kagawa et al. 2021). These naïve human PSCs are derived from the inner cell mass cells in the blastocysts or the primed PSCs using culture conditions that block various differentiation-inducing pathways (reviewed in (Pera and Rossant 2021)). Compared to conventional human PSCs that are maintained in the primed state, they display a broader developmental potential and can readily differentiate into the trophectoderm lineage upon induction (Guo et al. 2021; Io et al., 2021). To initiate blastocyst-like structure formation, the authors aggregated the naïve human PSCs in non-adherent hydrogel microwells, and cultured them in the presence of a combination of inhibitors and cytokines of key pathways regulating the specification of epiblast (EPI) and trophectoderm (TE) lineages. Specifically, they used the Hippo and TGF $\beta$ pathway inhibitors 
Table 1 Human stem cell-based embryo models

\begin{tabular}{|c|c|c|c|c|}
\hline Reference & Starting cells & Culture media & Culture condition & $\begin{array}{l}\text { Blastoids } \\
\text { formation }\end{array}$ \\
\hline Fan et al. (2021) & hEPS in LCDM + hEPS-derived TE-like cells & IVC1, IVC2 & AggreWell & 6 days \\
\hline Liu et al. (2021) & hiPSC in t2iLGoY & iBlastoid & AggreWell & 6 days \\
\hline Yu et al. (2021) & Naïve hPSC in 5i/L/A or PXGL & HDM, TDM & AggreWell & 9 days \\
\hline Yanagida et al. (2021) & Naïve hPSC in PXGL & $P D+A 83+Y, A 83, N 2 B 27$ & U-bottom 96-well & 3 days \\
\hline Sozen et al. (2021) & hEPS in hEP & $\mathrm{IVF}+\mathrm{hEP}+\mathrm{hTS}\left(5 \% \mathrm{O}_{2}\right)$ & AggreWell & 6 days \\
\hline Kagawa et al. (2021) & Naïve hPSC in PXGL & $\mathrm{N} 2 \mathrm{~B} 27+\mathrm{Y}, \mathrm{PALLY}, \mathrm{LY}$ & $\begin{array}{l}\text { Non-adherent hydrogel } \\
\text { microwell }\end{array}$ & 4 days \\
\hline
\end{tabular}

LCDM: N2B27 with $10 \mathrm{ng} / \mathrm{ml}$ human LIF, $3 \mu \mathrm{M}$ CHIR99021, $2 \mu \mathrm{M}$ (S)-(+)-Dimethindene maleate and $2 \mu \mathrm{M}$ minocycline hydrochloride, $1 \mu \mathrm{M}$ IWR endo-1, and $2 \mu \mathrm{M}$ $\mathrm{Y}-27632$

IVC1: Advanced DMEM/F12, 20\% Heat-inactivated FBS, 2 mM L-glutaMAX, 0.5\% penicillin/streptomycin, 1\% ITS-X, 1\% sodium pyruvate, $8 \mathrm{nM} \beta$-estradiol, 200 ng/mL progesterone and $25 \mu \mathrm{M} \mathrm{N}$-acetyl-L-cysteine

IVC2: Advanced DMEM/F12, 30\% Knockout serum, $2 \mathrm{mM} \mathrm{L-glutaMAX,} \mathrm{0.5 \%} \mathrm{penicillin/streptomycin,} 1 \%$ ITS-X, $1 \%$ sodium pyruvate, $8 \mathrm{nM} \beta$-estradiol, $200 \mathrm{ng} / \mathrm{mL}$ progesterone, $2 \mu \mathrm{M}$ Y27632 and $25 \mu \mathrm{M} \mathrm{N}$-Acetyl-L-cysteine

t2iLGoY: 50:50 mixture of DMEM/F-12 (ThermoFisher) and neurobasal medium (ThermoFisher), supplemented with $2 \mathrm{mM} \mathrm{L-glutamine} \mathrm{(ThermoFisher),} 0.1 \mathrm{mM}$ 2-mercaptoethanol (ThermoFisher), 0.5\% N2 supplement (ThermoFisher), 1\% B27 supplement (ThermoFisher), 1\% penicillin-streptomycin (ThermoFisher), 10 ng/ $\mathrm{ml}$ human leukaemia inhibitory factor (LIF, made in house), $250 \mu \mathrm{M} \mathrm{L-ascorbic} \mathrm{acid} \mathrm{(Sigma),} 10 \mu \mathrm{g} / \mathrm{ml}$ recombinant human insulin (Sigma), $1 \mu \mathrm{M}$ PD0325901 (Miltenyi Biotec), $1 \mu \mathrm{M}$ CHIR99021 (Miltenyi Biotec), $2.5 \mu \mathrm{M}$ Gö6983 (Tocris), and $10 \mu \mathrm{M}$ Y-27632 (ROCK inhibitor; Selleckchem)

iBlastoid: 50:50 mixture of DMEM/F-12 (ThermoFisher) and neurobasal medium (ThermoFisher), supplemented with $2 \mathrm{mM} \mathrm{I-glutamine} \mathrm{(ThermoFisher),} \mathrm{0.1} \mathrm{mM}$ 2-mercaptoethanol (ThermoFisher), 0.5\% N2 supplement (ThermoFisher), 1\% B27 supplement (ThermoFisher), and 1\% penicillin-streptomycin (ThermoFisher)) 5i/L/A: N2B27 basal medium with $1 \times$ GlutaMAX (Gibco), $1 \times$ nonessential amino acids (Gibco), $0.1 \mathrm{mM} \beta$-mercaptoethanol (Gibco), $0.5 \%$ penicillin-streptomycin (Gibco), $50 \mathrm{mg} / \mathrm{ml}$ bovine serum albumin (BSA, Sigma) and the following small molecules and cytokines: $1 \mu$ M PD0325901 (Stemgent), 0.5 or $1 \mu$ M IM-12 (Enzo), $0.5 \mu \mathrm{M}$ SB590885 (R\&D systems), $1 \mu \mathrm{M} \mathrm{WH-4-023} \mathrm{(A} \mathrm{Chemtek),} 20 \mathrm{ng} / \mathrm{ml}$ recombinant human LIF (Peprotech) and $10 \mathrm{ng} / \mathrm{ml}$ activin A (Peprotech). PXGL medium: $\mathrm{N} 2 \mathrm{~B} 27$ basal medium with $1 \times$ GlutaMAX, $1 \times$ nonessential amino acids, $0.1 \mathrm{mM} \beta$-mercaptoethanol, $0.5 \%$ penicillin-streptomycin and the following small molecules and cytokines: $1 \mu \mathrm{M}$ PD0325901, $2 \mu \mathrm{M}$ XAV939 (Sigma), $2 \mu \mathrm{M} \mathrm{Go6983} \mathrm{(Sigma)} \mathrm{and} 20 \mathrm{ng} / \mathrm{ml}$ recombinant human LIF

HDM: 1:1 (v/v) mixture of DMEM/F12 and neurobasal medium, $1 \times \mathrm{N} 2$ supplement, $1 \times \mathrm{B} 27$ supplement, $1 \times \mathrm{GlutaMAX}, 1 \times$ nonessential amino acids, 0.1 mM $\beta$-mercaptoethanol, $0.5 \%$ penicillin-streptomycin, $20 \mathrm{ng} / \mathrm{ml} \mathrm{bFGF} \mathrm{(Peprotech),} 20 \mathrm{ng} / \mathrm{ml}$ activin A and $3 \mu \mathrm{M}$ CHIR99021

TDM: $1: 1(\mathrm{v} / \mathrm{v})$ mixture of DMEM/F12 and neurobasal medium, $0.5 \times \mathrm{N} 2$ supplement, $0.5 \times \mathrm{B} 27$ supplement, $0.5 \%$ ITS-X, $0.5 \times$ GlutaMAX, $0.5 \times$ nonessential amino acids, $0.1 \mathrm{mM} \beta$-mercaptoethanol, 0.5\% knockout serum replacement (KSR, Gibco), 0.1\% FBS, $50 \mathrm{mg} \mathrm{ml} \mathrm{-} 1$ BSA, $0.5 \%$ penicillin-streptomycin, $1 \mu \mathrm{M}$ PD0325901, $0.5 \mu \mathrm{M}$ A83-01, $0.25 \mu \mathrm{M}$ SB590885, $0.5 \mu \mathrm{M}$ WH-4-023, $0.25 \mu \mathrm{M} \mathrm{IM-12,} 1 \mu \mathrm{M}$ CHIR99021, $0.5 \mu \mathrm{M}$ SB431542, $10 \mathrm{ng} \mathrm{ml}-1$ recombinant human LIF, 25 ng ml - 1 EGF, $0.75 \mu \mathrm{g} \mathrm{ml}-1$ l-ascorbic acid and $0.4 \mathrm{mM}$ VPA. For certain experiments the following chemicals were added to the TDM: $100 \mathrm{nM}$ Go6976 (Selleckchem), $1 \mu$ M Go6983 (Selleckchem), $10 \mu \mathrm{M} \mathrm{PKCa} \mathrm{(C2-4)} \mathrm{inhibitor} \mathrm{peptide} \mathrm{(Cayman),} 10 \mu \mathrm{M}$ PKC pseudosubstrate inhibitor (Cayman), $10 \mu \mathrm{M}$ PKCn pseudosubstrate inhibitor (Sigma) or $10 \mu \mathrm{M}$ PKC $\delta$ inhibitor KAI-9803 (delcasertib hydrochloride, MedChemExpress)

$\mathrm{PD}+\mathrm{A} 83+\mathrm{Y}: \mathrm{N} 2 \mathrm{~B} 27$ supplemented with $1.5 \mathrm{mM}$ PD0325901, $1 \mathrm{mM} \mathrm{A83-01} \mathrm{and} 10 \mathrm{mM} \mathrm{Y}-27632$

A83: N2B27 supplemented with $0.5 \mathrm{mM}$ A83-01

N2B27 + PALLY: N2B27 supplemented with PD0325901 (1 $\mu \mathrm{M})$, A 83-01 (1 $\mu \mathrm{M}$, MedChemExpress, HY-10432), 1-Oleoyl lysophosphatidic acid sodium salt (LPA)32 (500 nM, Tocris, 3854), hLIF (10 ng/ml), and Y-27632 (10 $\mu \mathrm{M})$

hEP: N2B27 supplemented with $10 \mathrm{ng} / \mathrm{ml}$ recombinant human LIF (L, $10 \mathrm{ng} / \mathrm{ml}$; Peprotech, 300-05), CHIR99021 (C, 1 mM; Stem Cell Technologies), (S)-(+)-Dimethindenemaleate (D, 1 mM; Tocris, 1425) and Minocycline hydrochloride (M, $2 \mathrm{mM}$; Santa Cruz Biotechnology, sc-203339), Y-27632 (5 $\mu \mathrm{M})$ IVF + hEP + hTS: 50\% IVF media (Continuous Single Culture-NX Complete (CSCM-NXC)) (90,168, FUJIFILM), 25\% hEP media, and $25 \%$ hTS media, supplemented with

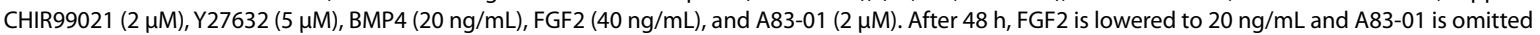

to promote TE formation, the ERK inhibitor and LIF to support the EPI fate, and the ROCK inhibitor to presumably reduce cell death. Under this condition, the cells efficiently and consistently self-organized to form blastocyst-like structures or blastoids. The blastoids contain a TE-like outer shell with apical-basal polarity and tight junctions, which expresses TE markers. They also have inner cell mass-like cell clusters that can further develop into EPI-like cells and primitive endoderm (PrE)-like cells. Importantly, the authors showed that only the naive but not primed human PSCs can form the blastoids, suggesting that the broad developmental potential of the naïve PSCs is critical for this process.
Next, the authors validated the identities of the cells in the blastoids by single-cell and bulk RNA sequencing. Based on gene expression profiles, the blastoid cells were found to mainly exist in three distinct states that are largely similar to the EPI, TE, and PrE lineages in normal blastocysts. Notably, unlike previous attempts, the blastoid cells can be clearly distinguished from cells isolated from the post-implantation stage embryos. Functionally, the blastoids can give rise to naïve human PSCs and TSCs, and the derived naïve PSCs can again generate $2^{\text {nd }}$ blastoids. In addition, the specification and morphogenesis of TE-like cells in the blastoids are dependent on atypical PKC and Hippo signaling, two pathways known to be critical in TE differentiation. Furthermore, the sequence 
of lineage marker expression and the appearance of the EPI, TE, PrE lineages follow the same order as observed in normal blastocyst development. Finally, the authors tested how the blastoids can be used to model implantation in vitro. They first developed a $2 \mathrm{D}$ open-faced endometrial layer (OFEL) system that responds to hormones in a similar fashion as the uterine endometrium at the time of implantation. The authors found that human naïve PSC-based blastoids only attached to the hormonestimulated OFEL cells but not the un-stimulated ones, and the attachment occurs at the polar TE region of the blastoids and requires the presence of the EPI-like cells. After attachment to OFEL, the EPI-, TE-, PrE-like cells continued to expand upon prolonged culture. The TElike cells formed trophoblasts expressing chorionic gonadotropin $\beta$, and further differentiated into syncytio- and extravillous trophoblasts. The EPI-like cells maintained pluripotency gene expression but up-regulated primed and epithelialization markers. Therefore, the blastoids and OFEL system may indeed be used to uncover new molecular details in peri- and post-implantation events.

Blastoids can help to uncover the developmental trajectories and milestones in early embryonic development, such as compartmentalization, lineage segregation, and implantation. Previous human PSC-based blastoid models were not able to recapitulate all the features of the developing blastocysts. Specifically, although blastocyst-like structures have been created from human expanded pluripotent stem cells, induced pluripotent stem cells, or naïve pluripotent stem cells cultured in a different condition, they showed significant divergence from natural blastocysts in marker expression, signaling pathways, cell composition, and cell identity (Sozen et al. 2021), especially in the TE lineage (Zhao et al. 2021). These limitations put significant constraints on their utility for modeling embryogenesis. The current study made great strides by using a naïve human PSC model with demonstrated developmental potentials toward TE, and by optimizing culture conditions to support the expansion of both the EPI and TE lineages (for comparison across the methods, please see Table 1). As a result, the blastoids generated in this study appeared to better approximate normal blastocysts in cell type constitution, and the EPI-, TE-, and PrE-like cells also seem to show better similarity to their in vivo counterparts. As TE is essential for implantation and epiblast patterning during gastrulation, this new blastoid model may thereby provide a better tool to study early human development. In addition, the successful formation of blastocyst-like structures using only human naïve PSCs supported the notion that the paradigm of early lineage segregation is different between human and mouse. Human pre-implantation epiblast cells and cultured PSCs were found to retain the ability to generate trophoblasts (Guo et al. 2021; Io et al. 2021). In contrast, mouse PSCs are restricted from differentiating into TE, and mouse PSC-based blastoids can only mimic germ layer specifications but not replicate the cell lineages in the blastocysts (Rossant and Tam 2021). Together, this study highlighted the importance in the choice of the starting cell type(s) and culture conditions in the stemcell based human embryo model.

\section{Abbreviations \\ PSC: Pluripotent stem cells; EPI: Epiblast; TE: Trophectoderm TSC Trophoblast stem cells; TSC: Trophoblast stem cells; PrE: Primitive endoderm; OFEL: Open- faced endometrial layer \\ Acknowledgements \\ Not applicable \\ Authors' contributions \\ XW and GH wrote the manuscript. All the authors read and approved the final manuscript. \\ Funding \\ This work is supported by the Intramural Research Program of the $\mathrm{NIH}$, National Institute of Environmental Health Sciences [Z01ES102745 to G.H., in part].}

Availability of data and material

Not applicable

\section{Declarations}

Ethics approval and consent to participate

Not applicable

\section{Consent for publication}

Not applicable

Competing interests

The authors declare that they have no competing interests.

Accepted: 6 January 2022

Published online: 14 January 2022

\section{References}

Fan Y, Min Z, Alsolami S, Ma Z, Zhang E, Chen W, Zhong K, Pei W, Kang X, Zhang $P$, et al. Generation of human blastocyst-like structures from pluripotent stem cells. Cell Discov. 2021;7:81.

Guo G, Stirparo GG, Strawbridge SE, Spindlow D, Yang J, Clarke J, Dattani A, Yanagida A, Li MA, Myers S, et al. Human naive epiblast cells possess unrestricted lineage potential. Cell Stem Cell. 2021;28:1040-1056.e1046.

Io S, Kabata M, lemura Y, Semi K, Morone N, Minagawa A, Wang B, Okamoto I, Nakamura T, Kojima Y, et al. Capturing human trophoblast development with naive pluripotent stem cells in vitro. Cell Stem Cell. 2021;28:10231039.e1013.

Kagawa, H., Javali, A., Khoei, H.H., Sommer, T.M., Sestini, G., Novatchkova, M., Scholte Op Reimer, Y., Castel, G., Bruneau, A., Maenhoudt, N., et al. (2021). Human blastoids model blastocyst development and implantation. Nature.

Liu X, Tan JP, Schroder J, Aberkane A, Ouyang JF, Mohenska M, Lim SM, Sun YBY, Chen J, Sun G, et al. Modelling human blastocysts by reprogramming fibroblasts into iBlastoids. Nature. 2021;591:627-32. 
Pera MF, Rossant J. The exploration of pluripotency space: Charting cell state transitions in peri-implantation development. Cell Stem Cell. 2021;28:1896-906.

Posfai E, Lanner F, Mulas C, Leitch HG. All models are wrong, but some are useful: Establishing standards for stem cell-based embryo models. Stem Cell Reports. 2021;16:1117-41.

Rossant J,Tam PPL. Opportunities and challenges with stem cell-based embryo models. Stem Cell Reports. 2021;16:1031-8.

Sozen B, Jorgensen V, Weatherbee BAT, Chen S, Zhu M, Zernicka-Goetz M. Reconstructing aspects of human embryogenesis with pluripotent stem cells. Nat Commun. 2021;12:5550.

Yanagida A, Spindlow D, Nichols J, Dattani A, Smith A, Guo G. Naive stem cell blastocyst model captures human embryo lineage segregation. Cell Stem Cell. 2021;28:1016-1022.e1014

Yu L, Wei Y, Duan J, Schmitz DA, Sakurai M, Wang L, Wang K, Zhao S, Hon GC, Wu J. Blastocyst-like structures generated from human pluripotent stem cells. Nature. 2021;591:620-6.

Zhao, C., Reyes, A.P., Schell, J.P., Weltner, J., Ortega, N., Zheng, Y., Björklund, A..K., Rossant, J., Fu, J., Petropoulos, S., et al. (2021). Reprogrammed iBlastoids contain amnion-like cells but not trophectoderm. bioRxiv, 2021.2005.2007.442980.

\section{Submit your manuscript to a SpringerOpen ${ }^{\odot}$ journal and benefit from:}

- Convenient online submission

- Rigorous peer review

- Open access: articles freely available online

- High visibility within the field

- Retaining the copyright to your article

Submit your next manuscript at $\boldsymbol{\nabla}$ springeropen.com 